\title{
How Much Do Adjuvant and Nozzles Models Reduce the Spraying Drift? Drift in Agricultural Spraying
}

\author{
Fabiano Griesang*, Ricardo Augusto Decaro, Cícero Antônio Mariano dos Santos, \\ Eduardo Souza Santos, Nelson Henrique de Lima Roque, Marcelo da Costa Ferreira
}

Nucleus of Study and Development at Technology of Application-NEDTA, São Paulo State University (Unesp), School of Agricultural and Veterinarian Sciences, Jaboticabal City, Brazil

Email: *fgriesang@hotmail.com

How to cite this paper: Griesang, F., Decaro, R.A., dos Santos, C.A.M., Santos, E.S., de Lima Roque, N.H. and da Costa Ferreira, M. (2017) How Much Do Adjuvant and Nozzles Models Reduce the Spraying Drift? Drift in Agricultural Spraying. American Journal of Plant Sciences, 8, 2785-2794. https://doi.org/10.4236/ajps.2017.811188

Received: September 5, 2017

Accepted: October 21, 2017

Published: October 24, 2017

Copyright $\odot 2017$ by authors and Scientific Research Publishing Inc. This work is licensed under the Creative Commons Attribution International License (CC BY 4.0).

http://creativecommons.org/licenses/by/4.0/

\section{c) (i) Open Access}

\begin{abstract}
The spraying of herbicides in crops has become the main form of weed control. Although it means unexpected effects on non-target plants resulted by spraying drift. Thus, improvements in application techniques, as the best selection of spray nozzles and adjuvant, are essential to avoid environmental contamination and economic losses. On this work, we evaluate how much adjuvant associated with nozzles can reduce the spray drift. The nozzles used at experiment were air induction flat tip, hollow cone and twinjet and the spray liquids, which were composed of herbicide glyphosate and phosphatidylcholine + propionic acid adjuvant. Measurements were made at wind tunnel and droplet sizer, at laser diffraction method. The models of nozzles influence in droplet size characteristics and in occurrence of spray drift. The use of adjuvants reduces the spray drift only combined with the twinjet nozzle, while for the other models the adjuvant did not reduce the global spray drift at significant levels. The adjuvant reduced the spray drift until $39 \%$, while the nozzles model reduced until $74 \%$. Both techniques when combined were able to reduce until $80 \%$. The model of nozzle has the biggest result on drift mitigation and the use of adjuvants can increase the drift mitigation specially with nozzles that produces smallest droplets.
\end{abstract}

\section{Keywords}

Droplet Size, Uniformity of Droplets, Span, Volumetric Median Diameter, Safe Application

\section{Introduction}

The spraying drift is associated with meteorological conditions at the spraying 
moment and the size of the droplet used, that cause impacts to non-target organisms [1]. To reduce this impact, legislation and communities are imposing increase of droplets sizes. Hydraulic nozzles with air induction technology can result in significantly gains with reduction of the volume of spraying susceptible to drift [2] and it has been adopted to drift reduction.

The model of nozzle has great importance on the drift potential, mainly when we compare different droplet formation, as the air induction technology, flat fan and hollow cone nozzles. So, an important reduction of spraying drift can be possible with the correct choosing of the nozzle type [3] [4]. The adoption of smallest droplets, aiming at bigger coverage values, results also in larger amount of drift [5]. On the other hand, the adoption of biggest size of droplets can result in losses of spraying liquid with the bounce and runoff on the leaves surface [6]. Those kinds of losses can be avoided with right choose of nozzle model and work pressure or with use of adjuvants with specific properties. In case of nozzles with air induction technology, it can bring good effects on the spraying drift reduction with the smallest droplets and improve the retention of the biggest droplets [3] [6].

So, the combination to the type of nozzle and the composition of the spraying liquid affects the drift potential [7], where some mixtures can give results with different nozzles, with better and worst results for each one, due the action on the physical-chemical characteristics of the spraying liquid. It causes changes in the instant of the partition of droplets on the spray jet, changing the size and the uniformity of the droplets [6] [8].

Identifying the best method of drift reduction can bring us the possibility of reducing drift losses, increasing the efficiency of applications and reducing environmental contamination. So, the aim of this work was to characterize the droplets produced by flat fan nozzle, air induction and hollow cone nozzles with spraying liquids composted of glyphosate with and without adjuvants and quantify the spray drift.

\section{Material and Methods}

\subsection{Local and Treatments}

The experiment was conducted in fully randomized design, with six treatments, composed by three models of nozzles and two spraying liquids, with four repetitions.

The models of nozzles were: air induction flat (AIXR11002VP), hollow cone (TXA8002VK) and twinjet (TJ60 11002VK). All of the nozzles had the same flow rate $\left(0.79 \mathrm{~L} \cdot \mathrm{min}^{-1}\right)$ with pressure of $3.0 \mathrm{bar}$. The spraying liquids was constituted by gliphosate $\mathrm{ATAR}^{\circledast}$ [Isopropylamine salt of $\mathrm{N}$-(phosphonomethyl) glycine (GLYPHOSATE) $480 \mathrm{~g} \cdot \mathrm{L}^{-1}$ (48\% w/v); Acid equivalent of GLYPHOSATE 356 $\mathrm{g} \cdot \mathrm{L}^{-1}\left(35.6 \% \mathrm{~m} \mathrm{v}^{-1}\right)$; Concentration of inert ingredients $679 \mathrm{~g} \cdot \mathrm{L}^{-1}\left(67.9 \% \mathrm{w} \cdot \mathrm{v}^{-1}\right)$, SL, ATAR DO BRASIL DEFENSIVOS AGRÍCOLAS LTDA.], considering the spraying volume $\left(80 \mathrm{~L} \cdot \mathrm{ha}^{-1}\right)$ and the dosage $\left(3 \mathrm{~L} \cdot \mathrm{ha}^{-1}\right)$ with and without the 
adjuvant LI-700 ${ }^{\circledR}$ [Mixture of Phosphatidylcholine (Lecithin) and Propionic Acid $712.88 \mathrm{~g} \cdot \mathrm{L}^{-1}\left(71.28 \% \mathrm{w} \cdot \mathrm{v}^{-1}\right)$ Inert Ingredients $\left.305.52 \mathrm{~g} \cdot \mathrm{L}^{-1}\left(30.55 \% \mathrm{w} \cdot \mathrm{v}^{-1}\right)\right]$ in the concentration of $0.125 \%$. The blue marker [FD\&C BLUE, product code: 220-405-35; Color Index: Food Blue \#2; Chemical Class: Triphenylmethane] $\left(0.6 \% \mathrm{~m} \cdot \mathrm{v}^{-1}\right)$ was added to measuring the deposits.

For the droplet size characterization and the drift measuring, evaluations were done with laser diffraction equipment and wind tunnel, respectively, which will be detailed next.

\subsection{Droplet Size Characterization}

For the droplet size characterization were used a Laser Diffraction Particle Size Analyzer (Mastersizer $S^{\oplus}$, version 2.19). The laser diffraction measures particle size distributions by measuring the angular variation in intensity of light scattered as a laser beam passes through a dispersed particulate sample. Large particles scatter light at small angles relative to the laser beam and small particles scatter light at large angles. The angular scattering intensity data is then analyzed to calculate the size of the particles responsible for creating the scattering pattern [9].

From the information generated by the Mastersizer software, the volumetric mean diameter (VMD), the coefficient of uniformity (Span) and the percentage of droplet volume with the size smaller than $100 \mu \mathrm{m}(<100 \mu \mathrm{m})$ were used. For Span determination, the droplet sizes that divided the spray volume in 10,50 and 90\% were used (DV0.1, DV0.5 and DV0.9), calculated by the relation between the differences of DV0.9 and DV0.1 by DV0.5 ((DV0.9-DV0.1)/DV0.5): the smaller the value, the more uniform the spray droplets. The parameter $<100$ $\mu \mathrm{m}$ corresponds to droplet sizes that are more susceptible to drift.

The spraying was driven by compressed air and the pressure was maintained with a precision pressure regulator. It was used a device to move the nozzles so that, in 1.5 second, all of the spray jet pass by the laser and through this collect, a representative sampling of all the droplet sizes produced by the nozzle is read.

The results for the uniformity coefficient (Span), Volumetric median diameter (VMD) and volume of droplet with size smaller than $100 \mu \mathrm{m}(<100 \mu \mathrm{m})$ were submitted to variance analyze by the $\mathrm{F}$ Test and the means were compared by the Tukey test (5\% of probability).

\subsection{Drift Evaluation in Wind Tunnel}

The tests were carried out in wind tunnel of open circuit, built in masonry, with two meters of height and width and 20 meters of length. The air flow was boosted by a double helix axial fan, with diameter of $0.9 \mathrm{~m}$, powered by the engine power take-off (PTO) of $65 \mathrm{~kW}$. In front of the fan, there were a screen and a hive to uniform the direction of the air flow, suppressing the turbulence created by the fan.

The speed of the wind was evaluated by the anemometer (Extech A892160) 
located 5 meters downwind the fan, one-meter high from the tunnel floor.

The spraying was activated with a spray system similar to the agricultural sprayer (pression control, hydraulic circuit, return), with a tank with 50 Liters of capacity, spray boom with two nozzles spaced in $0.5 \mathrm{~m}(0.6 \mathrm{~m}$ from the tunnel floor) and an anemometer. $18 \mathrm{~L}$ of each spraying liquid were prepared.

The drift potential risk was quantified by the bright blue tracer collected in samplers positioned in the wind tunnel at 5, 10 and 15 meters from the spray boom and at 0.3, 0.5, 0.7, 0.9 and 1.1 meters from the floor. These samplers were constituted of polyethylene wires with $2 \mathrm{~mm}$ of diameter and $300 \mathrm{~mm}$ of length, fixed on metal supports, crosswise the direction of the wind.

The temperature and the relative humidity were registered in the beginning of each spraying by a digital thermohygrometer (Minipa MT-241), with precision of $0.1^{\circ} \mathrm{C}$ for temperature and $1 \%$ for relative humidity. All applications were carried out under conditions considered ideal for spraying, with temperature between 19.3 and 24.3 and relative humidity between $52 \%$ and $75 \%$.

Each procedure took about 3 minutes for spraying and 5 minutes for decantation of the particles suspended in the wind tunnel. After each treatment, all the system was washed with clean water.

Aliquots of the spraying liquids were separated in order to obtain concentration curves of the dyes in the spraying liquid. From the initial spraying liquid of each treatment, sequential dilutions were performed with $50 \%$ of distilled water and the samples of each dilution were separated. Thus, 16 solutions were obtained with concentrations of dye per liter of spraying liquid between 3000 and $0.092 \mathrm{~g} \cdot \mathrm{L}^{-1}$. These extracts were analyzed by the spectrophotometer and the results were used to create the equations necessary for the calculation of the concentration of dye extracted from the collectors after the applications of the treatments.

After the spraying, the wires were collected and placed in PVC tubes with 12.7 $\mathrm{mm} \times 500 \mathrm{~mm}$, filled with $25 \mathrm{~mL}$ of distilled water, where they were washed out with manual shaking (20 seconds). The solutions were analyzed by a spectrophotometer at $630 \mathrm{~nm}$.

The drift reduction potential was estimated using the value obtained from the sum of all the values found for each treatment. The highest drift value was used as the standard, and from this, the amount of drift reduction obtained in each other treatment was calculated. We calculate how much was attributed to the nozzle and to the adjuvant, including the value obtained from the combination of both drift reduction techniques. It was represented as a percentage of drift reduction.

\subsection{Statistical Analysis}

The data were analyzed by descriptive statistical techniques and the means were compared by the Tukey test ( $5 \%$ of probability). 


\section{Results}

The model of the nozzle influences on the droplet size characteristics and on the occurrence of spray drift. The use of adjuvants resulted in the reduction of spray drift only combined with the twinjet nozzles, while for the other models the adjuvant did not reduce the global spray drift at significant levels.

\subsection{Droplet size Characterization}

For the VMD parameter, the flat air-induction nozzle resulted in larger droplets, differing statistically from the others. For this model, the use of adjuvant resulted in a significant increase for VMD. The twinjet model resulted in the lowest VMD values (Figure 1).

For the percentage of volume of droplets smaller than $100 \mu \mathrm{m}$, the flat air-induction nozzles resulted in the lowest values, differing statistically from the others. The presence of the adjuvant was observed only for the twinjet nozzle, which presented the highest volume of droplets subject to drift in the absence of adjuvant.

For the Span parameter, the less uniform droplets were produced by the flat air-induction nozzles, where the use of adjuvant improved the uniformity. The twinjet results in more uniform droplets in the absence and presence of adjuvant, which resemble the hollow cone only in the presence of adjuvant.

\subsection{Drift Evaluation in Wind Tunnel}

The twinjet nozzle without adjuvant resulted in the largest amount of drift in all of the collectors in the wind tunnel. With the use of adjuvant, were observed decrease of drift on most of the collect points (Figure 2 and Figure 3). For the hollow cone nozzle, no significant difference was found in the occurrence of
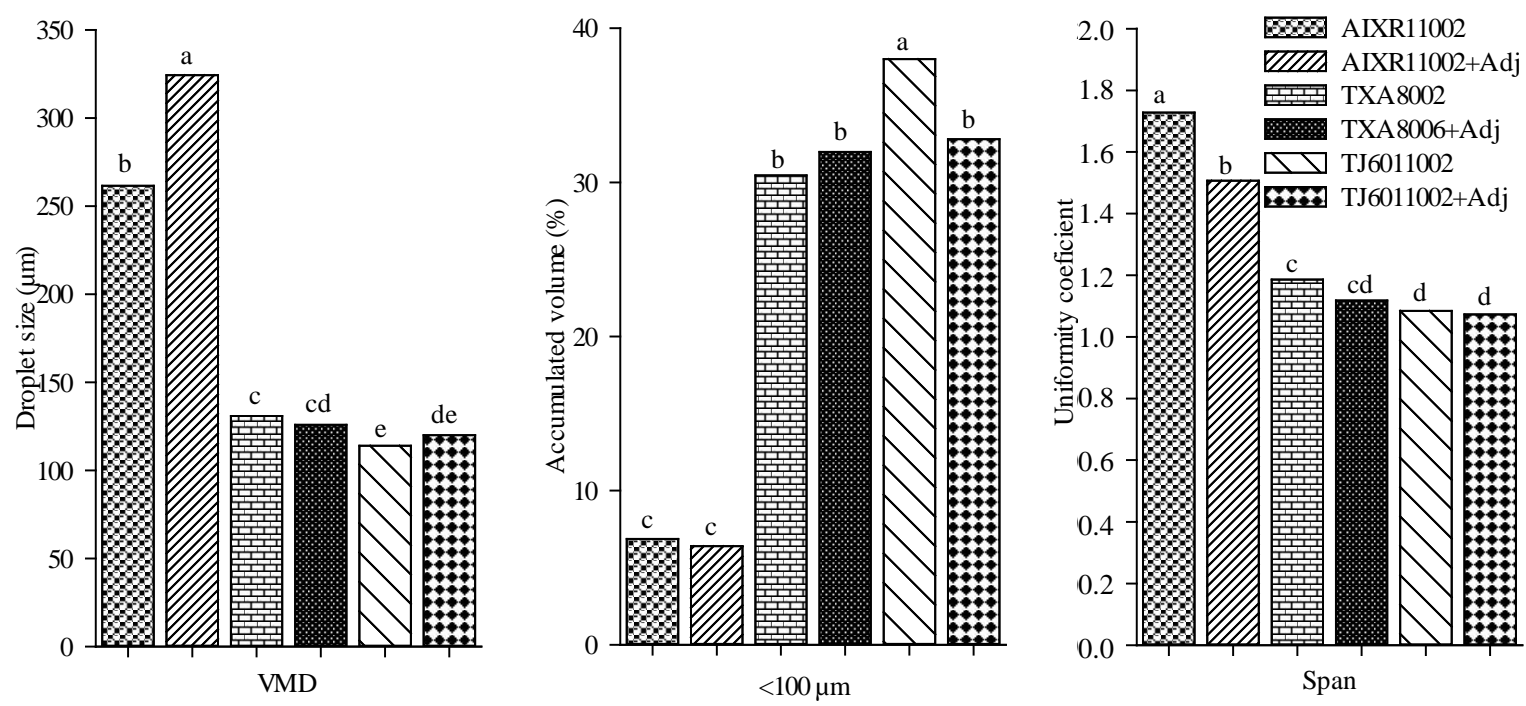

Figure 1. Volumetric median diameter (VMD), percentage in volume of droplet with size smaller than $100 \mu \mathrm{m}(<100$ $\mu \mathrm{m}$ ) and uniformity coefficient (Span). Columns with the same lower-case letters do not differ at $5 \%$ probability level at Tukey test. Least significant difference $(\mathrm{LSD})=7.29,3.04$ and 0.08 for VMD, <100 $\mu \mathrm{m}$ and Span, respectively. 


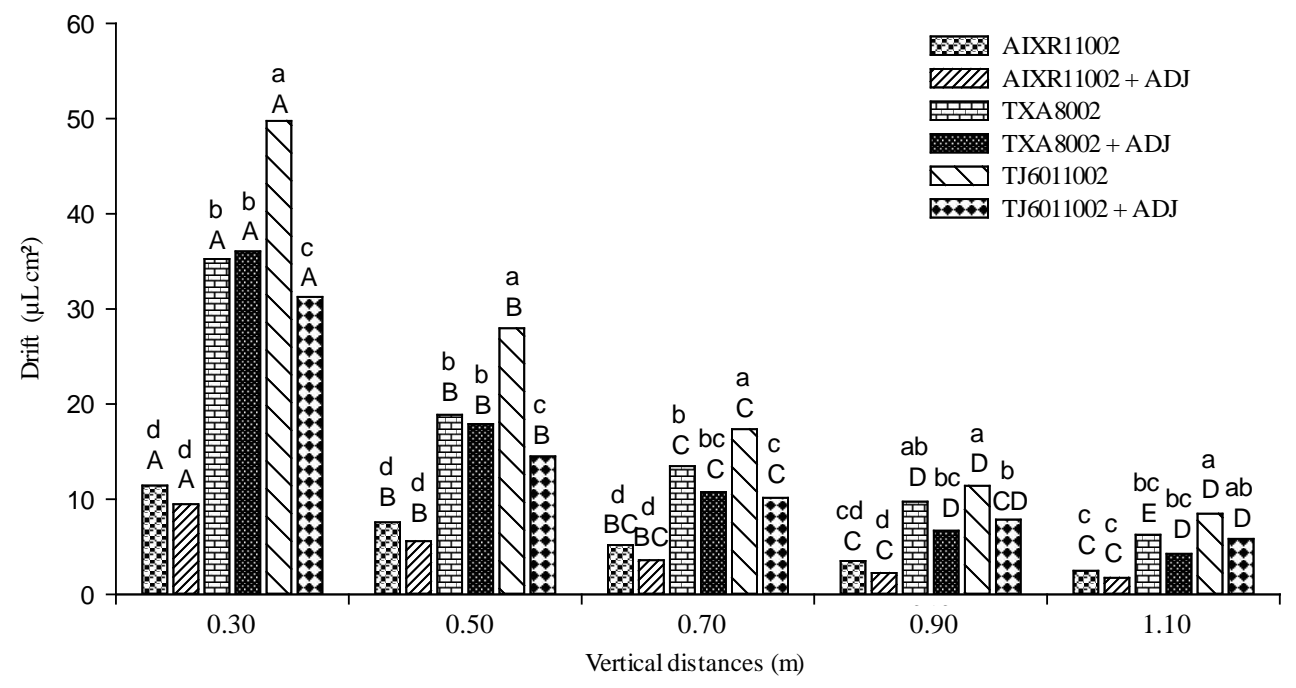

Figure 2. Amount of drift in $\mu \mathrm{L} \cdot \mathrm{cm}^{-2}$ for vertical distances. Columns with the same capital letters between the vertical points (LSD 3.28) and lower-case letter for treatments in each vertical point (LSD 3.14) do not differ at 5\% probability level at Tukey test.
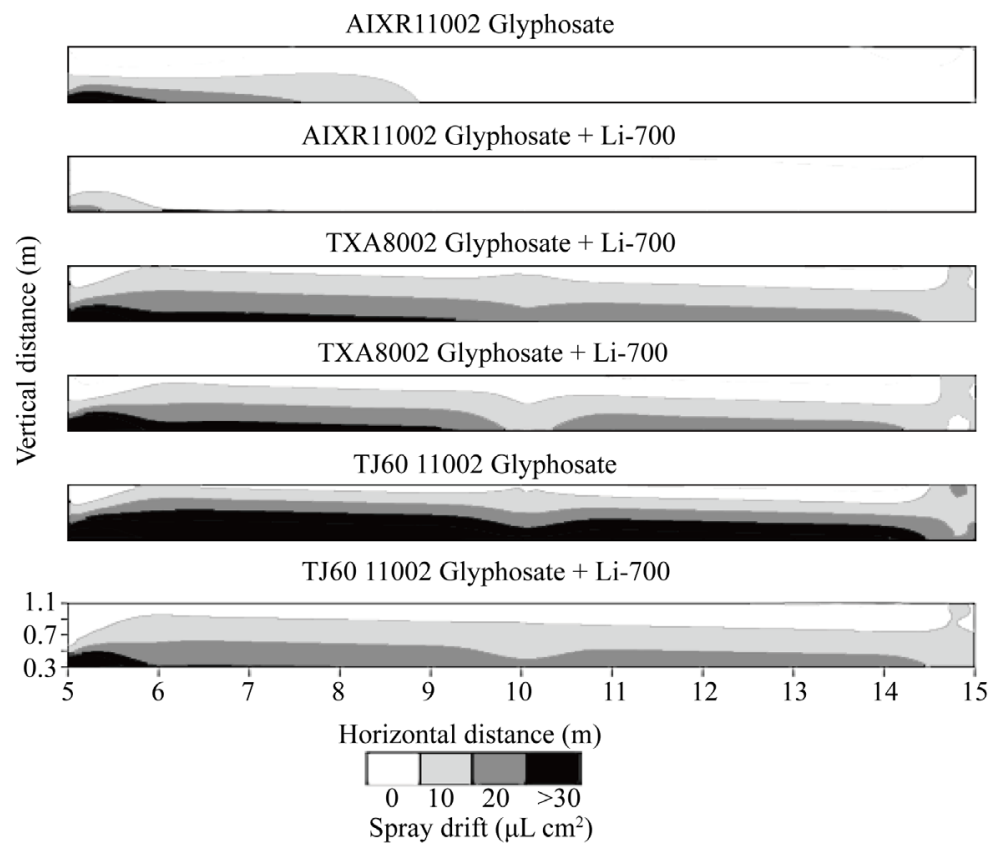

Figure 3. Spray drift mapping in the wind tunnel, considering the vertical and the horizontal distances for each nozzle and spraying liquid composition.

drift by the presence of adjuvants in the spraying liquid, presenting intermediate values in relation to the other analyzed models. The flat air-induction nozzle resulted in the smallest amount of drift in most of the collectors. The presence of adjuvant did not influence the drift with this model.

The lowest collectors $(0.3 \mathrm{~m})$ received the largest amount of drift for all of the nozzles and spray liquids analyzed, differing statistically from the other heights.

The quantification of the distribution of the droplets scattered by the wind in the wind tunnel allows the view of the behavior of droplets and thereby identify 
the relationship between the nozzle and the constitution of the spraying liquid, in order to improve the understanding of the importance of the correct configuration of the spray components (Figure 3).

The twinjet nozzle without adjuvant resulted in the largest amount of drift in all the horizontal points. With adjuvant, for this nozzle, the spray drift was significantly reduced in all the analyzed samples (Figure 3 and Figure 4). For the hollow cone nozzle, it was found a significant difference for the occurrence of drift in the presence of adjuvants only at the point of 10 meters. The air induction nozzle provided the lowest spray drift along the length of the wind tunnel, regardless of the presence of adjuvant.

All the nozzles analyzed promoted the highest amount of spray drift at the collector point located closer to the spray boom and to wind tunnel floor, values that differed significantly from the other collection distances.

We found a high correlation between all the parameters analyzed (Table 1). A negative correlation was found between the drift to the VMD and Span, which means that thinner spray droplets and lower coefficient of uniformity result in the greater amount of drift. On the other hand, the lower percentage in volume of droplets smaller than $100 \mu \mathrm{m}$ resulted in the least amount of drift (positive correlation).

Considering the drift reduction, the flat air-induction nozzle reduced the drift in almost $74 \%$ from the highest value of drift, encountered for the twinjet nozzle, without adjuvant. If we consider the potential of drift reduction attributed for the adjuvant, for the twinjet nozzle, the result was also very impressive: almost $40 \%$. When both drift reduction techniques were used combined, the drift reduction was around $80 \%$ (twinjet without adjuvant related to flat air-induction nozzle with adjuvant).

The other possible combinations did not produce significant results: for the

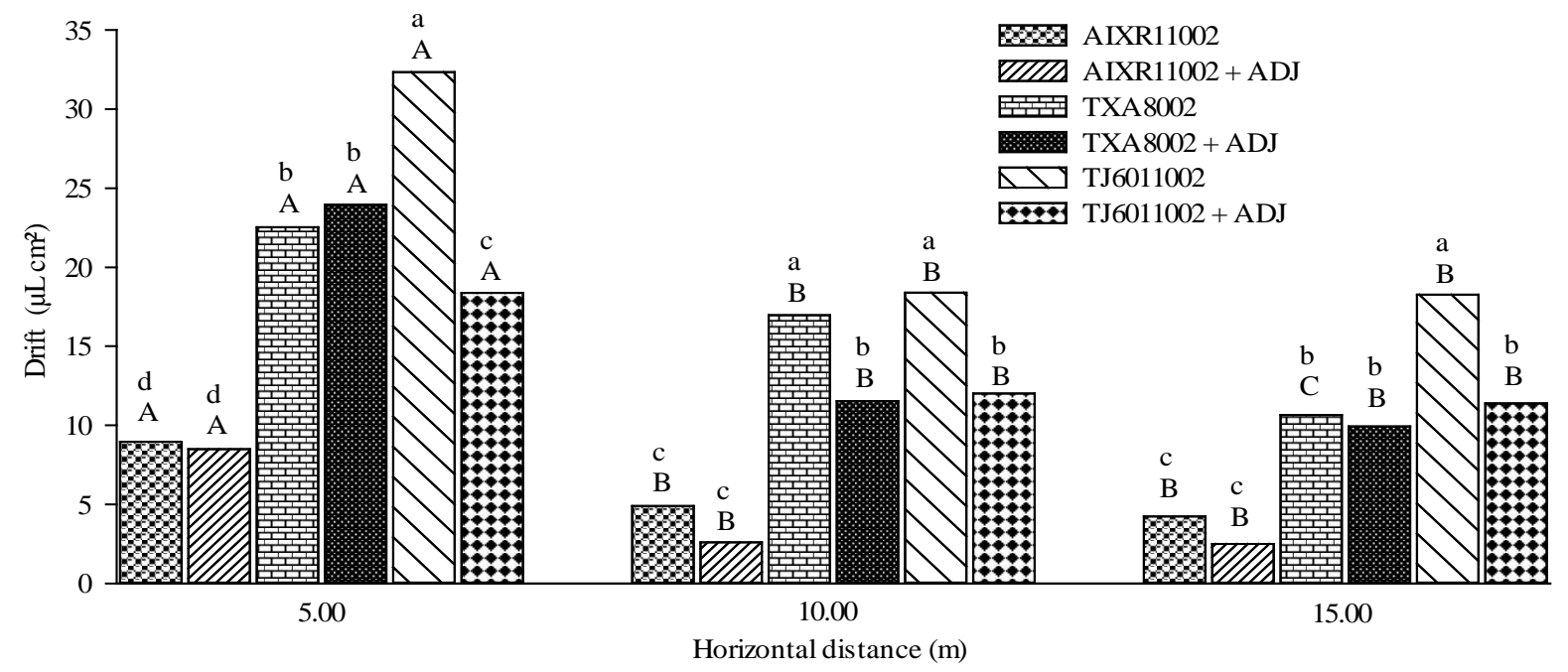

Figure 4. Amount of drift in $\mu \mathrm{L} \cdot \mathrm{cm}^{-2}$ for horizontal distances. Columns with the same capital letters between the horizontal points (LSD 2.25) and lower-case letter for treatments in each horizontal point (LSD 2.09) do not differ at 5\% probability level at Tukey test. 
Table 1. Pearson correlation analysis between drift and the three parameters of the droplet size characterization (VMD, Span and $<100 \mu \mathrm{m}$ ).

\begin{tabular}{cccc}
\hline & Drift & $\mathrm{VMD}^{\dagger}$ & Span \\
\hline VMD & $-0.8909^{* *}$ & - & - \\
& $<0.0001$ & - & - \\
Span & $-0.8180^{* *}$ & $0.86916^{* *}$ & - \\
& $<0.0001$ & $<0.0001$ & - \\
$<100 \mu \mathrm{m}$ & $0.93658^{* *}$ & $-0.9667^{* *}$ & $-0.9299^{* *}$ \\
& $<0.0001$ & $<0.0001$ & $<0.0001$ \\
\hline
\end{tabular}

${ }^{*}$ Significant at $0.01 \%$ probability. ${ }^{\dagger} \mathrm{VMD}$ : volumetric mean diameter; Span: uniformity coefficient; $<100$ $\mu \mathrm{m}$ : droplet volume with the size smaller than $100 \mu \mathrm{m}$.

hollow cone nozzles, addition of adjuvant resulted in a reduction of $9.5 \%$ of drift whereas for the air induction nozzle, addition of adjuvant resulted in drift reduction of $25 \%$, but for these nozzles, the values were already low, even those without adjuvant.

\section{Discussion}

The flat air-induction nozzles have the characteristic to produce larger droplets, that result in lower drift index when compared with nozzles of other technologies, as hollow cone or flat nozzles, regardless of the composition of the spraying liquid used [10] [11]. The percentage of drift produced by the flat air-induction nozzle with glyphosate andLi-700 adjuvant was significantly lower than the spraying liquid that only had glyphosate. This result is commonly found for spraying with this kind of adjuvant and nozzles that have the air-induction technology [4] [12].

The percentage in volume with smaller droplets $(<100 \mu \mathrm{m})$ is influenced by the nozzle model and this information give us an idea about the amount of spray that will potentially be drifted [13]. This can be confirmed with the wind tunnel, where the flat air-induction nozzles, that have lower amount of smaller droplets, result in lower amount of drift on the samplers located in there [14].

As a rule, flat air-induction nozzles produce droplets less uniform when compared with massive droplets [3] [15]. This affirmation cannot be true when we modify the constitution of the spraying liquid, as when we add Li- $700^{\circ}$, resulting in large increases of the uniformity, especially for this kind of nozzles.

The occurrence of spray drift can be influenced by the spraying liquid constitution. In most of the cases, the spraying liquid with $\mathrm{Li}-700^{\circ}$ presented lower amount of spray drift than the spraying liquid with only glyphosate. The adjuvants can change the droplet spectrum and, if this change results in increase in the VMD or in the reduction of volume of droplets smaller than $100 \mu \mathrm{m}$, they can result in less drift [16] [17].

If the model of the nozzle and the constitution of the spraying liquid influence the droplet characteristic, the combination of these parameters can also produce 
unexpected results. Thus, the knowledge of the effect of the product on the droplets size formed with different nozzle models is very important [4] [12]. The use of adjuvants for the mitigation of the spray drift is not very relevant for flat air-induction nozzles because of the larger droplets that they produce. On the other hand, adjuvants can be very useful for fine droplets, which are commonly used to control fungal diseases and pests in agricultural crops, and they can be recommended to reduce spray drift in the field.

Considering the conditions that this research was carried out, it was evident the effect of Li- $700^{\circ}$ adjuvant in the reduction of drift with thinner droplets, as those produced by the twinjet, found in the wind tunnel. The adjuvant had no influence on the occurrence of drift to the air-induction nozzle (AIXR 11002), although it did show significant increases in DMV and improvements in droplet uniformity. Further researches should be done with other types of products, evaluating the effect of adjuvants and nozzles on the quality of droplets formed, the occurrence of spray drift, as well as the effectiveness of the treatments and the safety of the application.

\section{Conclusion}

The model of air-induction nozzle has the biggest influence on mitigation of drift of droplets, impacting more than $70 \%$, and combined with use of adjuvants the drift reduction reached $80 \%$, being good indication for safer applications.

\section{Acknowledgements}

The authors would like to thank the Coordination for the Improvement of Higher Education Personnel-CAPES, Brazil, Ministry of Education.

\section{References}

[1] Al Heidary, M., Douzals, J.P., Sinfort, C. and Vallet, A. (2014) Influence of Spray Characteristics on Potential Spray Drift of Field Crop Sprayers: A Literature Review. Crop Protection, 63, 120-130. https://doi.org/10.1016/j.cropro.2014.05.006

[2] Etheridge, R.E., Womac, A.R. and Mueller, T.C. (1999) Characterization of the Spray Droplet Spectra and Patterns of Four Venturi-Type Drift Reduction Nozzles. Weed Science Society of America, 13, 765-770.

[3] Ferguson, J.C., O’Donnell, C.C., Chauhan, B.S., Adkins, S.W., Kruger, G.R., Wang, R., Ferreira, P.H. and Hewitt, A.J. (2015) Assessing the Deposition and Canopy Penetration of Nozzles with Different Spray Qualities in an Oat (Avena sativa L.) Canopy. Crop Protection, 81, 14-19. https://doi.org/10.1016/j.cropro.2015.11.013

[4] Gandolfo, M.A., Chechetto, R.G., Carvalho, F.K., Gandolfo, U.D. and Moraes, E.D. (2013) Influência de pontas de pulverização e adjuvantes na deriva em caldas com glyphosate. [Influence on Spray Drift of Nozzles and Adjuvants with a Glyphosate Spray Solution.] Revista Cência Agronômica., 44, 474-480. https://doi.org/10.1590/S1806-66902013000300008

[5] Fritz, B.K., Hoffmann, W.C. and Lan, Y. (2009) Evaluation of the EPA Drift Reduction Technology (DRT) Low-Speed Wind Tunnel Protocol. Journal of ASTM International, 6, 1-11. https://doi.org/10.1520/JAI102129 
[6] Butler-Ellis M.C. and Tuck, C.R. (1999) How Adjuvants Influence Spray Formation with Different Hydraulic Nozzles. Crop Protection, 18, 101-109. https://doi.org/10.1016/S0261-2194(98)00097-0

[7] Hilz, E. and Vermeer, A.W.P. (2013) Spray Drift Review: The Extent to Which a Formulation Can Contribute to Spray Drift Reduction. Crop Protection, 44, 75-83. https://doi.org/10.1016/j.cropro.2012.10.020

[8] Ferguson, J.C., O’Donnell, C.C., Chauhan, B.S., Adkins, S.W., Kruger, G.R., Wang, R., Ferreira, P.H. and Hewitt, A.J. (2015) Determining the Uniformity and Consistency of Droplet Size across Spray Drift Reducing Nozzles in a Wind Tunnel. Crop Protection, 76, 1-6. https://doi.org/10.1016/j.cropro.2015.06.008

[9] Malvern (1997) Getting Started-Manual Mastersizer. 1.3, United Kingdom, 1-183.

[10] Butler-Ellis, M.C., Swan, T., Miller, P.C.H., Waddelow, S., Bradley, A. and Tuck, C.R. (2002) Design Factors Affecting Spray Characteristics and Drift Performance of Air Induction Nozzles. Biosystems Engineering, 82, 289-296.

[11] Ferguson, J.C., Chechetto, R.G., O’Donnell, C.C., Dorr, G.J., Moore, J.H., Baker, G.J., Powis, K.J. and Hewitt A.J. (2016) Determining the Drift Potential of Venturi Nozzles Compared with Standard Nozzles across Three Insecticide Spray Solutions in a Wind Tunnel. Pest Management Science, 72, 1460-1466.

https://doi.org/10.1002/ps.4214

[12] Chechetto, R.G., Antuniassi, U.R., Mota, A.A.B., Carvalho, F.K., Silva, A.C.A. and Vilela, C.M. (2013) Influência de pontas de pulverização e adjuvantes no potencial de redução de deriva em túnel de vento. [Influence of Spray Nozzles and Adjuvants in Drift Reduction Potential in Wind Tunnel.] Semin. Ciências Agrárias, 34, 37-46. https://doi.org/10.5433/1679-0359.2013v34n1p37

[13] Ferreira, M. da C., Leite, G.J. and Lasmar, O. (2013) Cobertura e depósito de calda fitossanitária em plantas de café pulverizadas com equipamento original e adaptado para plantas altas. [Coverage and Deposition of Spraying Liquids in Coffee Plants Sprayed with Original Equipment and Adapted to Tall Plants.] Bioscience Journal, 29, 1539-1548.

[14] Costa, A.G.F., Velini, E.D., Negrisoli, E., Carbonari, C.A., Rossi, C.V.S., Corrêa, M.R. and Silva, F.M.L. (2007) Efeito da intensidade do vento, da pressão e de pontas de pulverização na deriva de aplicações de herbicidas em pré-emergência. [Effect of Wind Intensity, Pressure and Nozzles on Spray Drift from Preemergence Herbicide Applications.] Planta Daninha, 25, 203-210. https://doi.org/10.1590/S0100-83582007000100023

[15] Visacki, V., Sedlar, A.D., Gil, E., Bugarin, R.M., Turan, J.J., Janic, T.V. and Burg, P. (2016) Effects of Sprayer Boom Height and Operating Pressure on the Spray Uniformity and Distribution Model Development. Applied Engineering in Agriculture, 32, 341-346. https://doi.org/10.13031/aea.32.11376

[16] Dorr, G.J., Hewitt, A.J., Adkins, S.W., Hanan, J., Zhang, H. and Noller, B. (2013) A Comparison of Initial Spray Characteristics Produced by Agricultural Nozzles. Crop Protection, 53, 109-117. https://doi.org/10.1016/j.cropro.2013.06.017

[17] Oliveira, R.B., Antuniassi, U.R. and Gandolfo, M.A. (2015) Spray Adjuvant Characteristics Affecting Agricultural Spraying Drift. Journal of the Brazilian Association of Agricultural Engineering, 35, 109-116. 